\title{
EXTRACTION OF NON-FERROUS METALS AND RHENIUM FROM LEAD DUSTS OF COPPER PRODUCTION
}

\author{
O.S. Baigenzhenov ${ }^{1}$, A. Akkenzheyeva ${ }^{2}$, M. Turkmenbayeva ${ }^{2, \bowtie,}$ \\ M. Kizdarbekova ${ }^{3}$ and M. D. Turan ${ }^{4}$ \\ ${ }^{1}$ Department of metallurgy, Satbayev University, 050013, Kazakhstan \\ ${ }^{2}$ Department of Ecology and Chemical Engineering, Yessenov University, 130000, Kazakhstan \\ ${ }^{3}$ World Languages Department, Khoja Ahmed Yassawi International Kazakh-Turkish \\ University, 161200, Kazakhstan \\ ${ }^{4}$ Department of Metallurgical and Materials Engineering, Firat University, 23119, Turkey \\ ఐE-mail: sangar_almas@mail.ru
}

\begin{abstract}
The recovery of copper, zinc and rhenium from copper melting dust was investigated using the two-step leaching method. The effects of leaching parameters such as leaching time, liquid/solid ratio, leaching temperature and hydrogen peroxide concentration were studied. Experiments were performed in two stages (1) recovery of copper and zinc, and (2) recovery of rhenium. The optimum leaching conditions for copper and zinc were found as follows: leaching time is $60 \mathrm{~min} ; \mathrm{H}_{2} \mathrm{SO}_{4}$ concentration $80 \mathrm{~g} / \mathrm{L}$; liquid/solid ratio is 3.0 ; leaching temperature is $80{ }^{\circ} \mathrm{C}$. Under these conditions, copper and zinc recovering yields were obtained at $90.5 \%$ and $92.5 \%$, respectively. Optimum leaching conditions for rhenium were also achieved as follows: leaching time is $90 \mathrm{~min}$; liquid/solid ratio is $3.0 \mathrm{~mL} / \mathrm{g}$ leaching temperature is $70^{\circ} \mathrm{C}$; and hydrogen peroxide concentration is $3.0 \%$. More than $97 \%$ Re was recovered under optimum leaching conditions of rhenium.
\end{abstract}

Keywords: Lead Dusts, Copper, Zinc, Rhenium, Leaching.

RASĀYAN J. Chem., Vol. 14, No.3, 2021

\section{INTRODUCTION}

Rhenium is an uncommon refractory metal. It has principal applications in industries due to its multiple valences and its ability to make super-hard alloys. ${ }^{1,2}$ The industrial demand for rhenium is drastically increasing due to its wide use in high-tech industry. In nature, rhenium does not have its minerals, so it occurs in the form of isomorphic inclusions in copper and molybdenum ores, and is also present in smaller quantities in uranium deposits. ${ }^{3-5}$ Therefore, it is very important to recover from various raw materials containing traces of rhenium. A large amount of dust-gas mixture is formed during the copper smelting process. This mixture is known to contain rhenium $\left(\mathrm{Re}_{2} \mathrm{O}_{7}\right)$ as well as various gases (e.g. $\left.\mathrm{SO}_{2}, \mathrm{SO}_{3}\right){ }^{6,7}$ Hence, dusts of copper sulfide smelting process are considered a resource for rhenium recovery. Since rhenium is enriched in waste of mineral processing plants, copper production wastes, and slags, it is considered as an additional rhenium source. ${ }^{8,9}$ Depending on the content and form of rhenium in the raw material, various technological methods of its recovery are proposed. ${ }^{10-12}$

Nowadays production of rhenium from lead dusts (LD) constantly improving. This interest is due to three facts 1) the dusts have a significant rhenium content, 2) dusts available for processing, and 3) the cost of raw materials is very low.

There are miscellaneous recycling methods of lead dusts including water leaching, acid leaching (atmospheric, autoclave, electrochemical) of raw materials in presence of various oxidants. The choice of leaching reagent depends on the chemical composition of the raw material. It can be solutions of sulfuric acid, hydrochloric acid, nitric acid, and sodium salts in presence of an oxidant. ${ }^{13,14}$

Oxidative roasting processes are also considered as perspective technologies of LD processing. The main goal of roasting processes is to convert the lowest rhenium valence compounds $\left(\mathrm{ReO}_{3}\right.$, $\mathrm{ReS}_{2}$, etc.) to rhenium heptoxide $\left(\operatorname{Re}_{2} \mathrm{O}_{7}\right)$ to produce rhenium-containing solutions. ${ }^{15}$ 
RASĀYAN J. Chem.

Vol. 14 | No. 4 |2304-2310| October- December | 2021

Compared to the pyrometallurgical processes hydrometallurgical processes are eco-friendlier because it emits nothing, is cost-effective, and saves energy ${ }^{16}$. Therefore, in this study, rhenium containing dusts of copper production has been valorized applying two-stage leaching. The primary task of this study was to research the extraction of rhenium, zinc and copper from LD using sulphuric acid under atmospheric conditions to understand the effect of sulphuric acid concentration, leaching temperature, leaching time and liquid-to-solid ratio.

\section{Material and Methods}

\section{EXPERIMENTAL}

The LD sample was obtained from electric furnaces from Zhezkazgan copper melting factories in Kazakhstan. XRF analysis was used to determine the chemical composition of samples. The main components of lead dust are lead, copper and zinc (Table-1). The rhenium content is $0.0312 \%$ or $312 \mathrm{~g} / \mathrm{t}$.

Table-1: Chemical Composition of LD

\begin{tabular}{c|c|c|c|c|c}
\hline № & Elements & Content, \% & № & Elements & Content, \% \\
\hline 1 & $\mathrm{Re}$ & 0.0312 & 10 & $\mathrm{Bi}$ & 0.034 \\
\hline 2 & $\mathrm{Cu}$ & 3.48 & 11 & $\mathrm{Ca}$ & 0.20 \\
\hline 3 & $\mathrm{Cd}$ & 0.9 & 12 & $\mathrm{Ag}$ & 0.0082 \\
\hline 4 & $\mathrm{Zn}$ & 12.35 & 13 & $\mathrm{Na}$ & 0.253 \\
\hline 5 & $\mathrm{~Pb}$ & 41.0 & 14 & $\mathrm{Ni}$ & 0.001 \\
\hline 6 & $\mathrm{Fe}$ & 0.43 & 15 & $\mathrm{Si}$ & 0.202 \\
\hline 7 & $\mathrm{As}$ & 1.16 & 16 & $\mathrm{Se}$ & 0.0003 \\
\hline 8 & $\mathrm{Mo}$ & 0.0023 & 17 & $\mathrm{Te}$ & 0.0007 \\
\hline 9 & $\mathrm{Tl}$ & 0.036 & 18 & $\mathrm{Sn}$ & 0.0145 \\
\hline
\end{tabular}

Semi-quantitative X-ray phase analysis showed that the basis of LD is lead and zinc sulfate (Fig.-1).

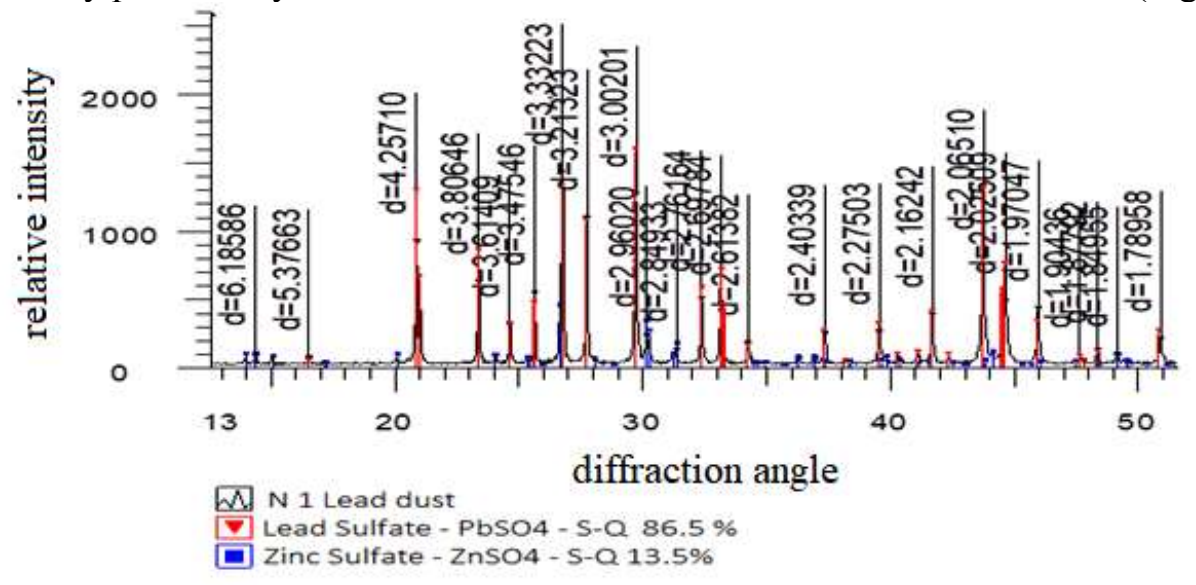

Fig.-1: Diffraction Pattern of LD

The method of chemical phase analysis of non-ferrous metals determined the quantitative content of sulfate, sulfide and oxide compounds of lead, zinc and copper (Table-2).

Table-2: Phase Composition of LD

\begin{tabular}{c|c|c|c}
\hline \multirow{2}{*}{ Element } & \multicolumn{3}{|c}{ Phase Content, \% } \\
\cline { 2 - 4 } & Sulfates & Oxides & Sulfides \\
\hline Lead & 93 & 4 & 3 \\
Zinc & 89 & 4 & 7 \\
Copper & 78 & 7 & 5 \\
\hline
\end{tabular}

\section{General Procedure}

All leaching experiments were carried out in a temperature-controlled three-necked flat bottom glass flask (cap. $250 \mathrm{~mL}$ ) on a hot-plate cum magnetic stirrer at fixed rpm (400) and a reflux condenser to avoid the 
loss due to evaporation. At the first stage of leaching, the applicability of water and sulfuric acid leaching was studied. The leaching time was recorded after successive addition of the LD and sulfuric acid solution to the reaction vessel, and then put this vessel in an oil bath maintained at a preset temperature (temperature range is $20-90{ }^{\circ} \mathrm{C}$ ). The second leaching stage was performed by usage of 3-9\% hydrogen peroxide solution in water. After each leaching experiment, the residue was filtered, rinsed with distilled water and dried in an oven at $75{ }^{\circ} \mathrm{C}$. The experiments were repeated three times to obtain reproducible results with an accuracy of $0.5 \%$.

\section{Detection Method}

The chemical composition of LD was analyzed using an iCAP 7200Duo inductively coupled plasma emission spectrometer. The phase composition of LD in terms of lead, copper, and zinc was determined by chemical phase analysis. The rhenium content in the processed products was determined using a spectrophotometric method based on the reaction of the rhenium complex of rhenium by a KFK-3-01ZOMZ photocolorimeter. The chemical composition of the leach solutions was analyzed on an Agilent Technologies 200 GTA 120 Graphite Tube Atomirer 240Z AA atomic absorption spectrometer.

\section{RESULTS AND DISCUSSION}

Water leaching experiments were performed to clarify the influence of temperature and leaching time on the recovery of copper, zinc and rhenium into the solution (Figs.-2 and 3). The obtained results revealed that the copper and zinc almost completely dissolved at low leaching temperature so that sulfate compounds have high dissolution properties. However, maximum recovery degree of metals was observed only under these leaching conditions: $\mathrm{t}=60-80^{\circ} \mathrm{C} ; \mathrm{S}: \mathrm{L}=1: 5 \mathrm{~g} / \mathrm{mL}$; time $=60$ minutes. Under these conditions, recovery of metals was $72 \%$ of $\mathrm{Cu}, 83 \%$ of $\mathrm{Zn}$, and $20.3 \%$ of Re.

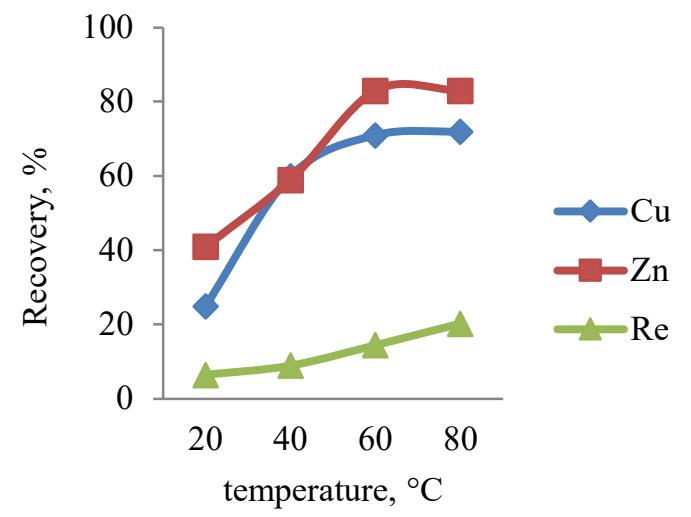

Fig.-2: Effect of Leaching Temperature (at 1:5 Solid/Liquids for $60 \mathrm{~min}$ )

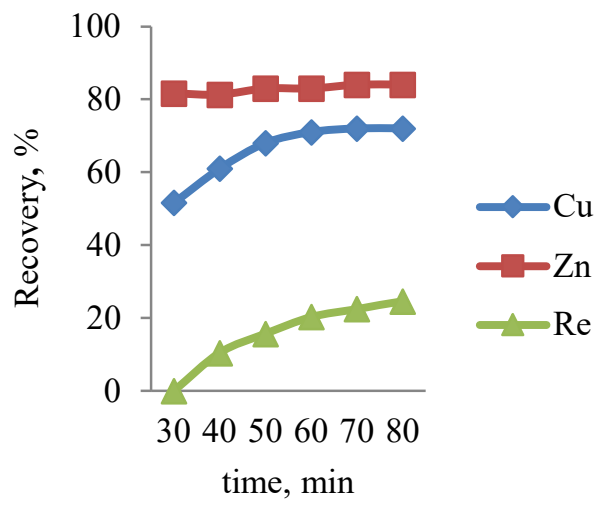

Fig.-3: Effect of Leaching Time (at 1:5 Solid/Liquids in $80^{\circ} \mathrm{C}$ )

The volume of the pregnant leach liquor is $491 \mathrm{~mL}$, metals content was determined as $5.03 \mathrm{~g} \mathrm{Cu} / \mathrm{L}, 20.8 \mathrm{~g}$ $\mathrm{Zn} / \mathrm{L}$, and $12.8 \mathrm{mg} \mathrm{Re} / \mathrm{L}$.

As can be seen, the recovery degree of non-ferrous metals does not exceed $90 \%$, which indicates the solubility of only sulphate compounds. To obtain satisfactory results on the recovery of valuable components from LD, further studies on leaching were performed by usage of sulfuric acid at a concentration of $20-110 \mathrm{~g} / \mathrm{L}$ (figure 4). The degree of zinc recovery in the solution increased by $10-11 \%$ compared to water leaching and reached $92.5 \%$. on leaching of LD by sulfuric acid solutions with a concentration of $20-50 \mathrm{~g} / \mathrm{L}$ and a temperature of $40{ }^{\circ} \mathrm{C}$. Under these conditions, the degree of copper recovery reached $84 \%$. Increasing the concentration of sulfuric acid to $80-110 \mathrm{~g} / \mathrm{L}$ caused $90.5 \%$ leaching of copper. On the other hand, it was seen that the rhenium resolution decreased up to $15.3 \%$. Concentration values of copper, zinc, and rhenium were determined as $68.0 \mathrm{~g} / \mathrm{L}, 23.6 \mathrm{~g} / \mathrm{L}$, and $9.6 \mathrm{mg} / \mathrm{L}$, respectively, whereas the sulfuric acid concentration decreased from $80 \mathrm{~g} / \mathrm{L}$ to $20 \mathrm{~g} / \mathrm{L}$. These findings showed that 
although sulfuric acid was used more than stoichiometric amount, all of the metals could not be taken into solution. It was also understood that there are major acid-consuming compounds are target metals in the solid material.

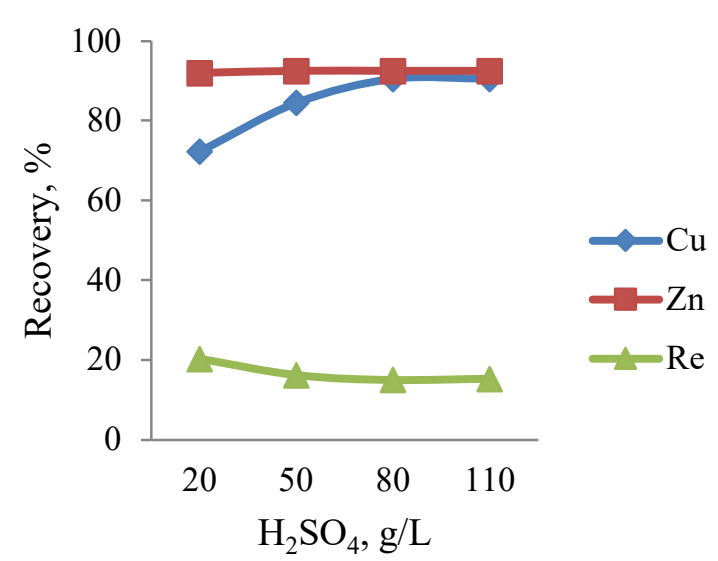

Fig.-4: Effect of Sulfuric Acid Concentration (60 min, $\left.\mathrm{S}: \mathrm{L}=1: 5,40^{\circ} \mathrm{C}\right)$

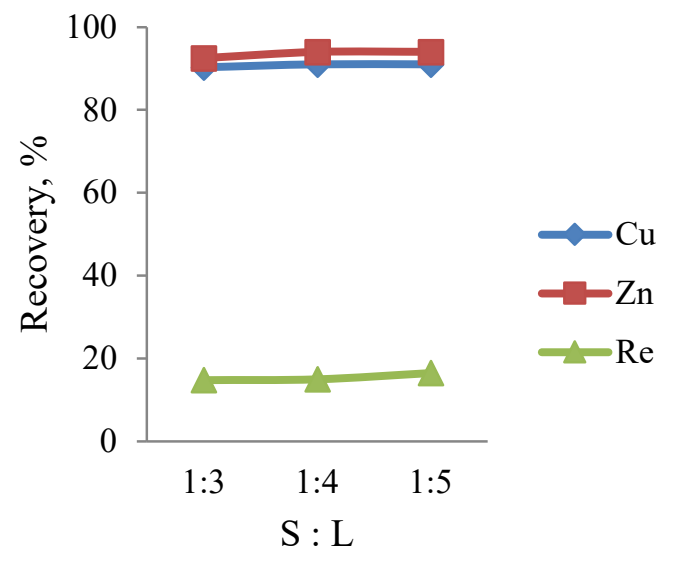

Fig.-5: Effect of the S:L Ratio (60 min, $80 \mathrm{~g} / 1$ $\left.\mathrm{H}_{2} \mathrm{SO}_{4}, 60^{\circ} \mathrm{C}\right)$

During sulfuric acid leaching of LD, the dissolution behavior of other metals was also investigated. The chemical composition of the leaching solution at $\mathrm{S}$ : $\mathrm{L}=1: 3$ and leaching temperature of $60^{\circ} \mathrm{C}$ is shown in table 3. It seems that the dissolution of other metals is quite low under these conditions.

Table-3: Chemical Composition of LD with Sulfuric Acid Leaching Solution, g/L

\begin{tabular}{c|c|c|c|c|c|c}
\hline $\mathrm{Cu}$ & $\mathrm{Zn}$ & $\mathrm{Cd}$ & $\mathrm{Pb}$ & $\mathrm{Na}$ & $\mathrm{Si}$ & $\mathrm{Re}$ \\
\hline 10.7 & 38.8 & 1.4 & 4.4 & 0.8 & 0.02 & 0.015 \\
\hline
\end{tabular}

The low degree of recovery of rhenium compared to non-ferrous metals is due to its forms of presence in LD in the form of lower oxide compounds. The results also showed that the rhenium in LD consists of different oxidation stages. To increase the degree of rhenium recovery, the presence of an oxidizer in leaching solutions is required. In previous research reported that hydrogen peroxide is proposed as an effective oxidizer, during the decomposition, not polluted solutions. ${ }^{16,17}$ It is shown that hydrogen peroxide is a temperamental aggravate, the disintegration of which can be catalyzed by certain variables, for example, the nearness of corrosive, base, mineral surface. Sulfuric acid leaching was performed in the presence of hydrogen peroxide. More than $90 \%$ recovery of rhenium was achieved in the study conducted in presence of an oxidant. Due to the high content of copper and zinc in the solutions of sulfuric acid leaching and their negative impact on the extraction-stripping of rhenium (contamination of the commercial rhenium salts with impurities of copper and zinc, etc.), we decided to conduct two-stage leaching. The first stage is sulfuric acid leaching with the recovery of copper and zinc, and the second stage is oxidative leaching of rhenium. It was observed that the dissolution of metals increased in the two-step leaching method.

The leach waste obtained from oxidative leaching in which $94.3 \%$ of rhenium was recovered from first stage leaching residue was characterized. Chemical composition was found as $42.1 \% \mathrm{~Pb}, 0.99 \% \mathrm{Zn}, 0.35$ $\% \mathrm{Cu}, 1.2 \% \mathrm{As}, 0.2 \% \mathrm{Si}$, and $0.028 \% \mathrm{Re}$. Based on semi-quantitative X-ray phase analysis of leaching waste, there are no peaks corresponding to zinc sulfate (Fig.-6).

The residue of first stage leaching was subjected to second stage leaching with 3-9\% solutions of hydrogen peroxide at $60{ }^{\circ} \mathrm{C}$ and $\mathrm{S}: \mathrm{L}=1: 3$. By leaching the leach residue with a $6 \%$ solution of hydrogen peroxide for 60 minutes, the maximum rhenium recovery is achieved as $96.1 \%$. A similar result $(95.6 \%)$ can be achieved by leaching with a $3 \%$ solution of hydrogen peroxide for 90 minutes (Fig.-7). An application of $\mathrm{H}_{2} \mathrm{O}_{2}$ distinctly improves rhenium leaching, but an increase in the concentration of hydrogen peroxide in 
RASĀYAN J. Chem.

Vol. 14 | No. 4 |2304-2310| October- December | 2021

the leaching solution above $6 \%$ does not lead to an increase in the extraction of rhenium into the solution. It is assumed that this limitation is due to an insufficient oxidizing strength of $\mathrm{H}_{2} \mathrm{O}_{2}$. Therefore, $3 \%$ solution of hydrogen peroxide was selected as optimum concentration for rhenium extraction from first stage leaching residue. The studies of S : L ratio and leaching temperature showed that $97.3 \%$ of rhenium was extracted under conditions of $70{ }^{\circ} \mathrm{C}$ and $\mathrm{S}: \mathrm{L}=1: 3$. Also, a similar result was obtained at $60{ }^{\circ} \mathrm{C}$ and $\mathrm{S}: \mathrm{L}=1: 5$ (Fig.-8).

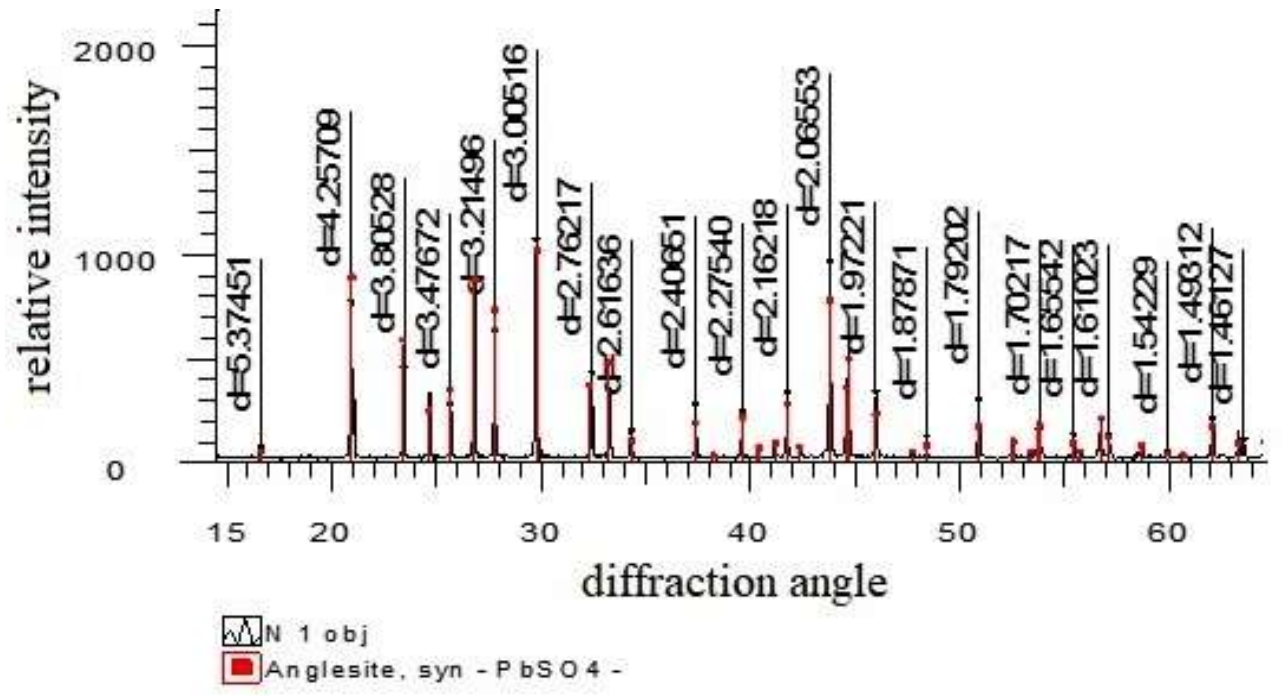

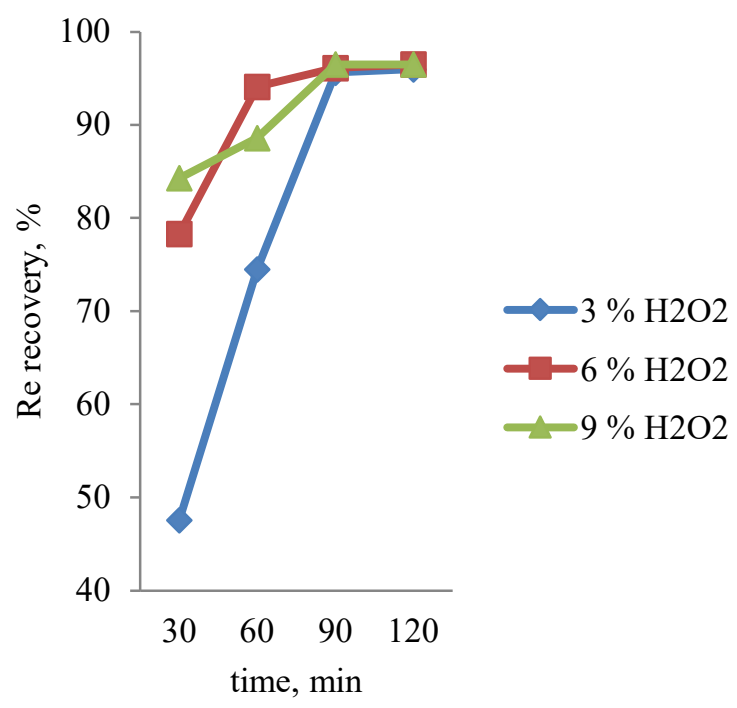

Fig.-7: Influence of Time and $\mathrm{H}_{2} \mathrm{O}_{2}$ Concentration on the Degree of Rhenium Recovery, $60^{\circ} \mathrm{C}, \mathrm{S}: \mathrm{L}=1: 3$

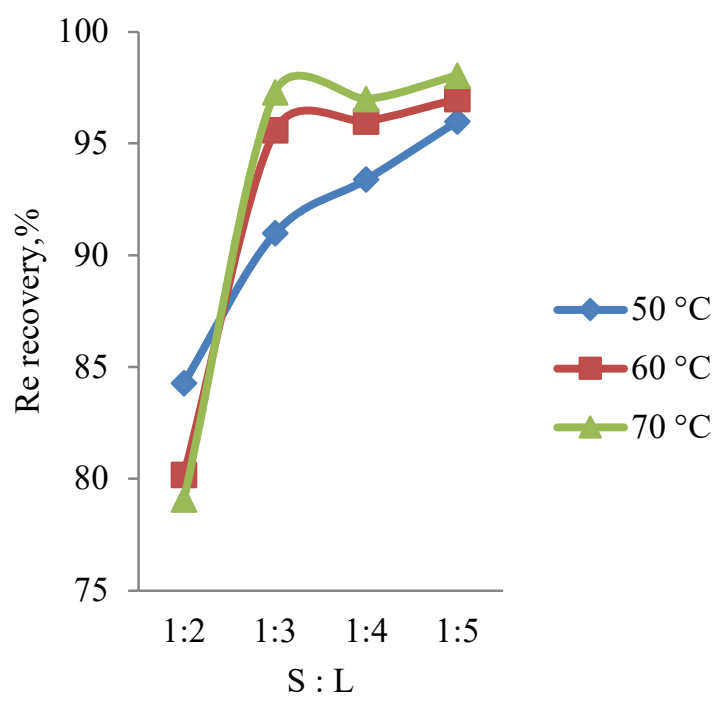

Fig.-8: Influence of Temperature and the S: L Ratio on the Degree of Rhenium Recovery, 90 $\min , 3 \% \mathrm{H}_{2} \mathrm{O}_{2}$

Nevertheless, to obtain more rhenium-concentrated solutions, it is proposed to conduct a leaching process at $70{ }^{\circ} \mathrm{C}, \mathrm{S}: \mathrm{L}=1: 3$ with a $3 \%$ solution of hydrogen peroxide. Chemical composition of the resulting solution, g / L: $0.092 \mathrm{Re}, 0.011 \mathrm{Cu}, 0.06 \mathrm{Zn}, 0.8 \mathrm{~Pb}, 0.9$ As. The resulting solutions are sent to the processes solvent extraction process. The developed flowsheet (technological scheme) of hydrometallurgical processing of LD is shown in Fig.-9.

\section{CONCLUSION}

As a result of studies of hydrometallurgical processing of lead dust of copper production, a method for 2stage leaching of raw materials has been developed. At the first stage of sulfuric acid leaching, copper and zinc ions were converted to a solution with recovery rates of $90.3 \%$ and $92.5 \%$, respectively. At the second stage of oxidative leaching, rhenium pregnant leach solutions with a recovery degree of $97.3 \%$ were 


\section{RASĀYAN J. Chem.}

Vol. 14 | No. 4 |2304-2310| October-December | 2021

obtained. Processing of rhenium-containing lead dusts by two-stage leaching allowed to obtain separate solutions of copper and zinc with their content of 10-11 g/L and 38-39 g / L, respectively, and solutions containing $90-92 \mathrm{mg} / \mathrm{L}$ of rhenium.

Lead Dust:

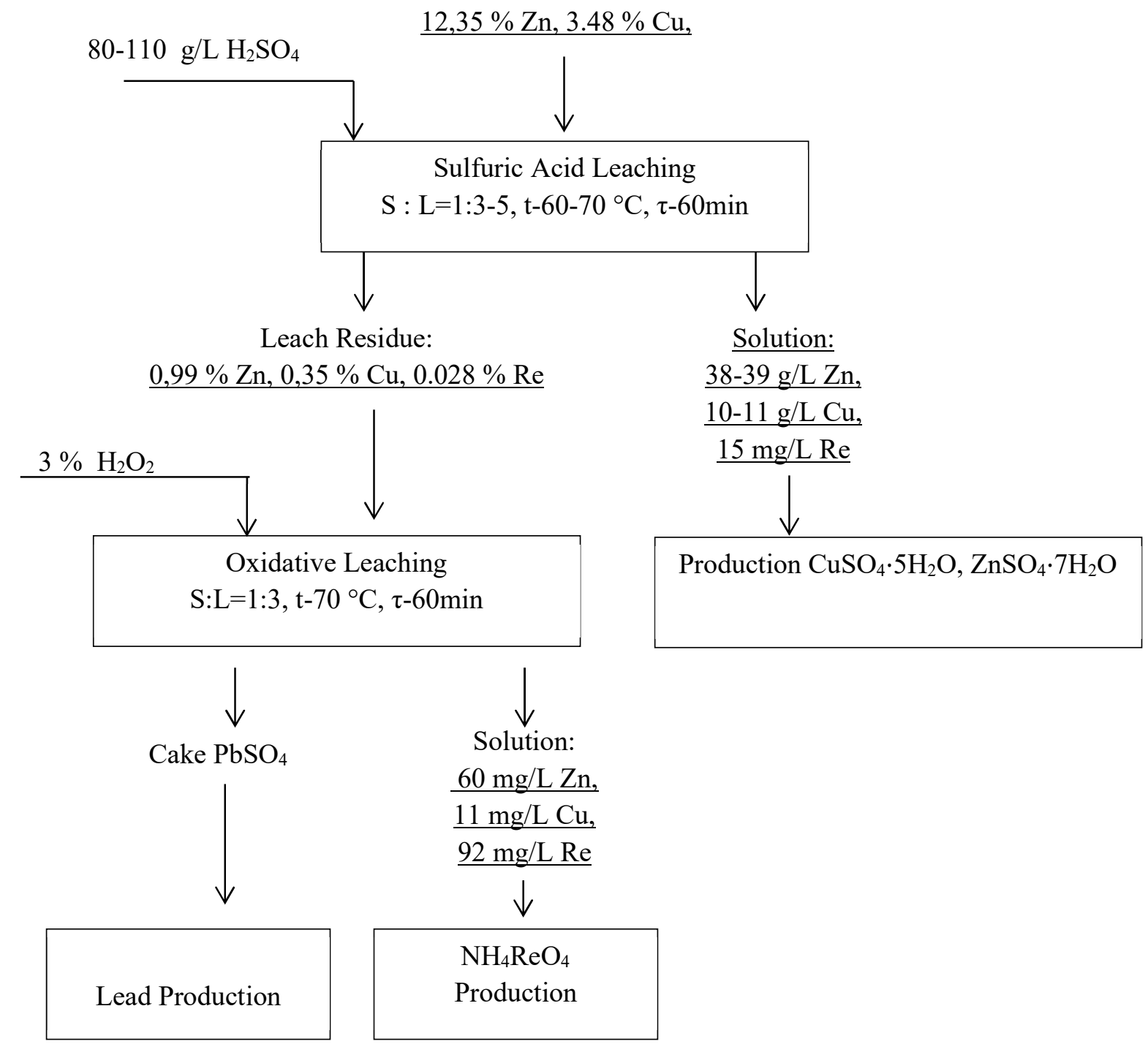

Fig.-9: The Flowsheet of Hydrometallurgical Processing of LD

\section{REFERENCES}

1. B.D. Bryskin, F.C. Danek, The Journal of The Minerals, Metals \& Materials Society, 43, 24(1991), https://doi.org/10.1007/BF03220616

2. E.M. Savitskii, M.A. Tylkina, S.I. Ipatova, E.I. Pavlova, Metal Science and Heat Treatment of Metals, 2, 483 (1960), https://doi.org/10.1007/BF00649725

3. I.F. Barton, C.A. Rathkopf, M.D. Barton, Mining, Metallurgy \& Exploration, 37, 21(2020), https://doi.org/10.1007/s42461-019-00145-0

4. Caelen Anderson, Patrick R. Taylor, Corby G Anderson, Minerals and Metallurgical Processing 30(1), 59(2013), https://doi.org/10.1007/BF03402342

5. U. Kesieme, A. Chrysanthou, M. Catulli, International Journal of Refractory Metals and Hard Materials, 82, 150(2019), https://doi.org/10.1016/j.ijrmhm.2019.04.006

6. R.P. Singh, G. Thomas, A. Wolfescott, A. Braymiller, International Journal of Refractory Metals and Hard Materials, 50, 79(2015), https://doi.org/10.1016/j.ijrmhm.2014.11.003 


\section{RASĀYAN J. Chem.}

Vol. 14 | No. 4 |2304-2310| October- December | 2021

7. A. K. Serikbaeva, K. K. Zhumashev, F. A. Bedrikulova, A. A. Suieubergenova, Russian Journal of Non-Ferrous Metals, 55, 519(2014), https://doi.org/10.3103/S1067821214060224

8. A. K. Serikbayeva, A. A. Suieybergenova, F. A. Berdikulova, Metalurgija, 54, 715(2015)

9. Z.S. Abisheva, A.N. Zagorodnyaya, N.S. Bekturganov, Hydrometallurgy, 109, 1(2011), https://doi.org/10.1016/j.hydromet.2011.04.014

10. A.K. Serikbayeva, N. Telegusova, B.B.Bekentaev, Metallurgijia, 52, 515(2013)

11. A.K. Serikbayeva, F.A. Berdikulova, K.K. Mamyrbayeva, Sh.K. Akilbekova. Metallurgija, 4, 345(2018).

12. N. Nebeker, J. B. Hiskey, Hydrometallurgy, 125-126, 64(2012), https://doi.org/10.1016/j.hydromet.2012.05.008

13. Entezari, M. Karamoozian, M. Eskandari Nasab, Journal of Mining and Environment, 4, 77(2013), http://dx.doi.org/10.22044/jme.2013.143

14. T. Helbig, S. Gilbricht, F. Lehmann, B. Daus, N. Kelly, R. Haseneder, C. Scharf, Minerals Engineering, 128, 168(2018), https://doi.org/10.1016/j.mineng.2018.08.028

15. H. Salehi, H. Tavakoli, M. R. Aboutalebi, H. R. Samim, Hydrometallurgy, 185, 142(2019), https://doi.org/10.1016/j.hydromet.2019.02.004

16. V.A. Kozlov, G.R. Saisanova, G.S. Sapargalieva, G.Z. Zhunusova, O.S. Baigenzhenov, N. Zhumakynbai, Research Journal of Pharmaceutical, Biological and Chemical Sciences, 6, 1308(2015)

17. M.D. Turan, H.S. Altundoğan, Metallurgical and Materials Transactions B, 44, 809(2013), https://doi.org/10.1007/s11663-013-9858-0

[RJC-6092/2020] 